\title{
Virtual Screening of Treated Pistachio vera Shell Powder as a Potential Sorbent in Sequestering Ubiquitous Divalent Metal Ions from Aqueous Matrices
}

\author{
N. SHYAMALA DEVI ${ }^{1}$, N. MUTHULAKSHMI ANDAL ${ }^{2 *}$ and K. VIVITHABHARATHI ${ }^{3}$ \\ 1,2Department of Chemistry, PSGR Krishnammal College for Women, \\ Peelamedu, Coimbatore, India. \\ ${ }^{3}$ Department of Chemistry, PSGR Krishnammal College for Women, \\ Peelamedu, Coimbatore, India. \\ ${ }^{*}$ Corresponding E-mail: muthulakshmiandal@psgrkc.ac.in
}

http://dx.doi.org/10.13005/ojc/340138

(Received: September 20, 2017; Accepted: December 05, 2017)

\begin{abstract}
Water pollution due to noxious heavy metals such as $\mathrm{Hg}(\mathrm{II}), \mathrm{Cr}(\mathrm{VI}), \mathrm{Cd}(\mathrm{II})$ and $\mathrm{Pb}(\mathrm{II})$ ions etc., has been tremendously focused gaining attention towards social benefit. Increasing concentrations of these metals into the ecosystem constitute a severe health hazard due to their toxicity, accumulation and bio-magnification throughout the food chain. Lead contamination of drinking water is a great threat through varied sources viz., lead pipes, plating units etc. Pistachio vera shell (PVS) is a hard layer that surrounds the delicious kernel of the nut. The current work evaluates the feasibility of powdered Pistachio vera shell (PVSP) - a biowaste for sequestering $\mathrm{Pb}$ (II) ions is treated with $0.1 \mathrm{~N} \mathrm{HCl}$ and $0.1 \mathrm{~N} \mathrm{NaOH}$ to enhance its sorption efficacy (TPVSP). SEM, FTIR and microscopic analyses are recorded for characterising the chosen sorbent. Batch experimental studies are performed to assess the equilibration between the sorbate and the sorbent. The competence of the sorbent material is experimentally verified through various operating factors viz., particle size and dosage of TPVSP, agitation time interval between TPVSP and $\mathrm{Pb}$ (II) ions, initial concentrations of $\mathrm{Pb}$ (II) ions, $\mathrm{pH}$ of the adsorption medium, effects of cations, anions, co-ions and influence of temperatures on $\mathrm{Pb}(\mathrm{II})$ - TPVSP system. The residual concentrations of $\mathrm{Pb}$ (II) ions from aqueous solutions are analysed using Atomic Absorption Spectrophotometer (Shimadzu-AA-6200). Langmuir and Freundlich models are applied to describe the adsorption capacity. Column studies are conducted to ensure the quantitative estimation of TPVSP in trapping $99 \%$ of sorbate species at a dose of $40 \mathrm{mg}$ the flow rate being, $100 \mathrm{ml} / 10 \mathrm{~min}$. assuring the bulkiness of the material.
\end{abstract}

Keywords: Pistachio vera shell, Lead, operating factors, Isotherms.

This is an $\mathbf{C}$ Open Access article licensed under a Creative Commons Attribution-NonCommercial-ShareAlike 4.0 International License (https://creativecommons.org/licenses/by-nc-sa/4.0/ ), which permits unrestricted NonCommercial use, distribution and reproduction in any medium, provided the original work is properly cited. 


\section{INTRODUCTION}

Contamination of heavy metals into aquatic bodies by various pollutants, causes deterioration in ecosystem ${ }^{1}$. They also accumulate in food chain by affecting human beings ${ }^{2}$. The principle sources of heavy metals include: tanneries, electroplating, electronics, waste streams from mining operations, petrochemical industries and textile mill products ${ }^{3}$. Vast number of treatment methods have been adopted for trapping heavy metals from wastewaters viz, chemical precipitation, ion exchange, filtration, adsorption, membrane separation, oxidation and reduction. Out of all the methods, sorption is a potential and promising alternative technique for sequestration of metals ${ }^{4}$. The boon of biosorption over conventional treatment methods comprises low cost, high efficacy, decreasing biological sludge, regeneration of biosorbent and feasibility of metal recovery. The present study is focussed on the exploration of screening a low cost, easily available material for better sorption onto heavy metal ions ${ }^{5}$. Huge variety of low cost biomaterials like cotton seed hulls, peanut hulls, almond shell, walnut shell , hazel nut shell, palm shell, areca catechu shell, chest nut shell have been widely used ${ }^{6-9}$. Pistachio vera nut shell (Pistacica vera $\mathrm{L}$ ) is the only edible crop of 11 species in the genus Pistacia and is one of the popular nuts tree ${ }^{10}$. The potentiality of Pistachio vera shell for removing $\mathrm{Pb}$ (II) ions from wastewater, is first of its kind with no reports elsewhere.

Lead is a pollutant present in air as well as in drinking water ${ }^{11}$. The problem conquers alarming proportions in industrialized countries and in big metropolitan conglomerates. In air, fuel automobiles cause lead emissions. In water, lead in the form of salts is released from lead treatment plants and from recovery industries such as metallurgical, electroplating and other chemical industries. Nearly $40 \%$ of lead production finds in battery manufacturing, finishing, ammunition, tetraethyl lead manufactories', painting, ceramic and glass industries, printing, dyeing etc. The permissible limit of lead in drinking water and surface water as set by EU,USEPA and WHO are 0.010, 0.015 and 0.010 $\mathrm{mg} / \mathrm{L}$ respectively ${ }^{12}$. Accumulation of lead in drinking water causes diseases such as nephritis, anaemia, abdominal pain, hypertension, nausea, vomitting, developmental defects and language difficulties (Kazoos et al., 2001/Tunali et al., 2006/ Gupta et al., $2009)^{13}$. In this background, the research survey had aimed at the utilization of modified Pistachio vera shell waste as an alternative novel adsorbent for the elimination of lead(II) ions from synthetic aqueous solution. Effect of process variables like $\mathrm{pH}$, particle size, sorbent dosage, initial $\mathrm{Pb}^{2+}$ ion concentration, cations, anions, co-ions and temperature efficiencies are studied, to assess the sorptive characteristics of the modified material.

\section{MATERIALS AND METHODS}

\section{Collection of Raw Material}

Pistachio vera shell (PVS) were collected from the Departmental stores in Coimbatore, Tamil Nadu, India. The collected materials were washed using distilled water followed by doubly distilled water in order to remove the impurities and dried in unclouded ambient air for a period of nearly ten days. The dried materials were then pounded using electrical mixer and sieved to various mesh sizes viz., 85BSS, 72BSS, 52BSS, 36BSS and 22BSS using Scientific Test Molecular Sieves manufactured by jayant Scientific Instruments Co., Mumbai.

\section{Chemicals Employed}

All the chemicals are of Analytical Grade, supplied by Merck \& Co. Doubly distilled water (Double Distillation Unit-4DQ) was used for preparation of solutions. Weighing were taken using Analytical Digital Balance (Denver Instruments).

\section{Preparation of Stock solution}

A stock solution of $1000 \mathrm{mg} / \mathrm{L}$ of $\mathrm{Pb}^{2+}$ ions was prepared by dissolving $1.5985 \mathrm{~g}$ of lead nitrate $\left[\mathrm{Pb}\left(\mathrm{NO}_{3}\right)_{2}\right]$ in doubly distilled water. A standard of $100 \mathrm{mg} / \mathrm{L}$ was prepared from the stock solution, and further dilutions were made as working aliquots as per the experimental requirements.

\section{Chemical Modifications}

The adsorbent (PVSP) of varying sieve sizes were first boiled in $0.1 \mathrm{~N} \mathrm{HCl}$ for three hours. After decanting the clear solution, the residue was boiled again in $0.1 \mathrm{~N} \mathrm{NaOH}$ for three hours. The treated sorbents of varying sizes were washed several times to attain neutral $\mathrm{pH}$ with doubly distilled water. The materials were soaked in doubly 
distilled water for sufficient amount of time, in order to protonate the surface which would make more sorption sites available and later dried. Only the

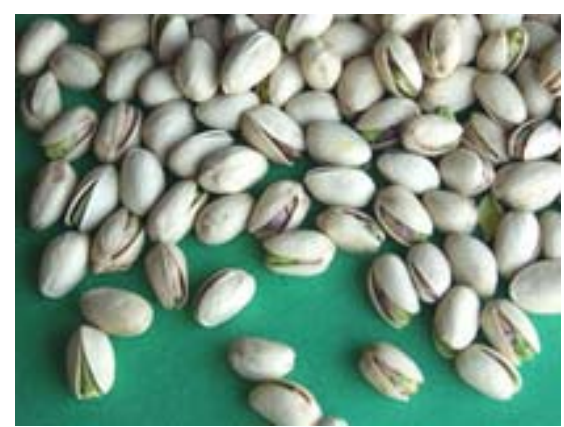

Fig. 1(a) Image of Raw Pistachio vera shell chemically Treated Pistachio vera shell powder (TPVSP) have been employed for further experiments.

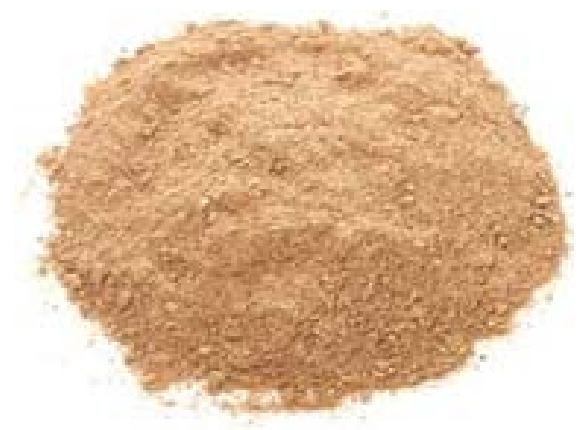

1(c) Image of Pistachio vera shell Powder

\section{Batch Experimental Studies}

The adsorption experiments were carried out varying the particle size, contact time, initial concentration, dosage, $\mathrm{pH}$ of the medium, influence of cation, anion, co-ions and effect of temperature to optimize the best condition for $\mathrm{Pb}$ (II)-TPVSP system. Varying initial concentrations of $\mathrm{Pb}(\mathrm{II})$ ions viz.,10, 25, 50, 75, $100 \mathrm{mg} / \mathrm{L}$ were prepared and $25,50,75,100 \mathrm{mg}$ dose of particles sizes viz., 0.18 $\mathrm{mm}, 0.21 \mathrm{~mm}, 0.30 \mathrm{~mm}, 0.42 \mathrm{~mm}$ and $0.71 \mathrm{~mm}$ of TPVSP were added into the $250 \mathrm{~mL}$ Erlenmeyer flasks, each containing $50 \mathrm{~mL}$ of the adsorbate. The contents of the flasks were stirred in a mechanical shaker (KEMI) at a speed of $140 \mathrm{rpm}$ for a contact time of $10 \mathrm{~min}$. Initial $\mathrm{Pb}$ (II) ion concentrations and the residual concentrations after filtration were analysed using Atomic Absorption Spectrophotometer (Shimadzu- AA 6200). Column experiments and desorption studies were

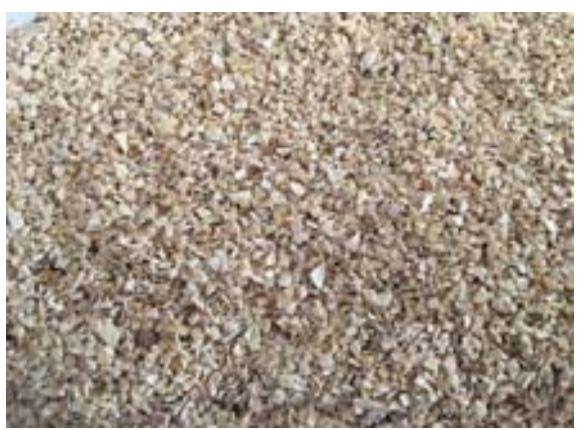

1(b) Image of Crushed Pistachio vera shell 
$\mathrm{C}_{1}=$ initial metal ion concentration $(\mathrm{mg} / \mathrm{L}), \mathrm{C}_{2}=$ residual metal concentration $(\mathrm{mg} / \mathrm{L}), \mathrm{V}=$ volume $(\mathrm{mL})$ of sorbate species, $\mathrm{M}=$ mass of the adsorbent $(\mathrm{mg})$.

\section{RESULTS AND DISCUSSION}

\section{Physio-Chemical Characteristic studies}

Various physiochemical characteristics were carried out to study the properties of the TPVSP viz., $\mathrm{pH}$ (Deluxe pH meter (Labtronics), conductivity (Elico (CM 180 Digital Conductivity Meter), Moisture content (Xylene-extraction Test Method (ASTM D 2867-95), Bulk density, Specific gravity and Ash content were determined and the results are presented in Table. 1.
Moisture content dilutes the adsorbents and therefore necessitates using of additional weight of adsorbents to provide the required weight, even though does not affect the adsorption power. Ash content generally gives an idea regarding inorganic constituents associated with carbon. The ash content of the material gives very low value, indicative of low quantity of inorganic matter and high quantity of the carbon content. This is in agreement with the percentage of carbon content (Table. 2).

Table. 2: Elemental Analysis

\begin{tabular}{lcc}
\hline S. No & Elements & $\%$ \\
1 & $\mathrm{C}$ & 44.46 \\
2 & $\mathrm{H}$ & 6.22 \\
3 & $\mathrm{~N}$ & 6.78 \\
4 & $\mathrm{~S}$ & Not detected \\
\hline
\end{tabular}

Table. 1: Physical characteristic of Pistachio vera shell $(0.18 \mathrm{~mm})$

\begin{tabular}{lcc}
\hline Factors & Methods/Instruments & Values \\
\hline $\mathrm{pH}(1 \%$ solution$)$ & pH meter & 6.5 \\
Conductivity $(\mathrm{mV})$ & Conductivity Meter & 40.16 \\
Bulk Density $(\mathrm{g} / \mathrm{L})$ & Specific gravity bottles & 0.54 \\
Moisture Content $(\%)$ & Xylene Method & 4.92 \\
Specific Gravity & Pycnometer & 1.46 \\
Ash Content $(\%)$ & Muffle Furnace & 0.8 \\
\hline
\end{tabular}

\section{CHNS Analysis}

Elemental analysis (ElementaryVario EL-III Germany CHNS Analyser) were performed to estimate the \% of $\mathrm{C}, \mathrm{H}, \mathrm{N}, \mathrm{S}$ present in the sorbent material, where carbon content is found to be approximately seven times greater than $\mathrm{H}$ and $\mathrm{N}$ elements as obvious from Table. 2 confirms that the higher $\mathrm{C} / \mathrm{H}$ for TPVSP implies higher content of aromatic carbon.

\section{Screening of the Material Characteristics}

The sorption efficiency of the Pistachio vera shell powder in sequestering $\mathrm{Pb}$ (II) ions is characterized by and microscopic studies, FT-IR, SEM and EDAX.

\section{Microscopic Analysis}

Image microscopic analysis were carried out to determine the particle sizes $(0.18 \mathrm{~mm}, 0.21$ $\mathrm{mm}, 0.30 \mathrm{~mm}, 0.42 \mathrm{~mm}$ and $0.71 \mathrm{~mm}$ ) corresponding to the categorized mesh sizes of the chosen material using binocular microscope (Optika make).
The microscopic image for $0.18 \mathrm{~mm}$ size of the chosen material is depicted in Fig. 3a-3c. Microscopic observation revealed that the adsorbent is mesoporous in nature, hence observed to possess good sorption capacity.

\section{IR Spectral Studies for treated and untreated Pistachio vera shell powder}

Fourier Transform Infrared Spectral data (Shimadzu) were recorded within the range of $400-4000 \mathrm{~cm}^{-1}$ for unloaded and metal(s) laden materials to determine the functional groups present in the sorbent that might have been involved in the metal uptake.

FTIR spectra of PVSP and TPVSP are shown in Fig. 4(a) \& 4(b). The broad peak around $3410 \mathrm{~cm}^{-1}$ correspond to $\mathrm{O}-\mathrm{H}$ stretching vibrations, due to inter and inter-molecular hydrogen bonding of polymeric compounds (macromolecular associations) such as alcohols, phenols and carboxylic acids, as in pectin, cellulose groups on 
the adsorbent surface. The peaks at 2916 and 2852 $\mathrm{cm}^{-1}$ are attributed to the symmetric and asymmetric $\mathrm{C}-\mathrm{H}$ stretching vibration of aliphatic acids. The peaks around $1395 \mathrm{~cm}^{-1}$ correspond to the symmetric bending of $\mathrm{CH}_{3}$. The peak observed at $1630 \mathrm{~cm}^{-1}$ is the stretching vibration of bond due to non-ionic carboxyl groups $\left(-\mathrm{COOH},-\mathrm{COOCH}_{3}\right)$, and may be assigned to carboxylic acids or their esters. Broad peak at $1072 \mathrm{~cm}^{-1}$ may be due to stretching vibration related to $\mathrm{C}-\mathrm{OH}$ of alcoholic groups and carboxylic acids (Mehrasbi et al., 2009) ${ }^{13}$. A comparison between metal loaded and unloaded spectra imply a minimum decrease in peak intensity. This can be attributed to the adsorption of the selected sorbate species.

\section{SEM Analysis}

Scanning Electron Microscopy (SEM) has been a primary tool for characterizing the surface morphology and the fundamental physical

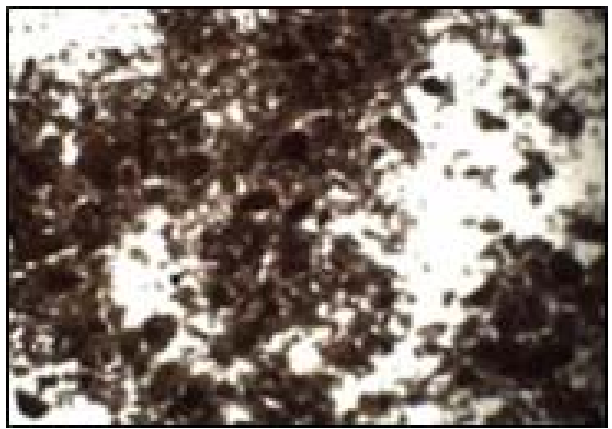

Fig. 3(a) Microscopic Image of Unloaded TPVSP properties of the material surface. It is useful for determining the particle shape, porosity, and appropriate particle size distribution (B.Armagan et al., 2012- Desalination and Water Treatment). The chemical examination of Pistachio vera shell powder (PVSP) was accomplished by using an energy dispersive X-ray spectrometer (ZEISS) attached to a scanning electron microscope. Direct observation of the surface microstructures of Pistachio vera shell Powder at the fixed sizes for the raw, treated and metal loaded are given in the SEM micrographs of Fig $5 a, 5 b, 5 c$ respectively. Porous nature exhibited by the raw PVSP indicate the good possibility for trapping $\mathrm{Pb}(\mathrm{II})$ ions. Chemical modifications of the raw sorbent have improved the porous nature with greater homogeneity. $\mathrm{Pb}$ (II) loaded sorbent presented has recorded a maximum distinguished dark spots indicative of effective adsorption (S.ParlayiciKaratas \& E.Pehliva., 2015) ${ }^{14}$

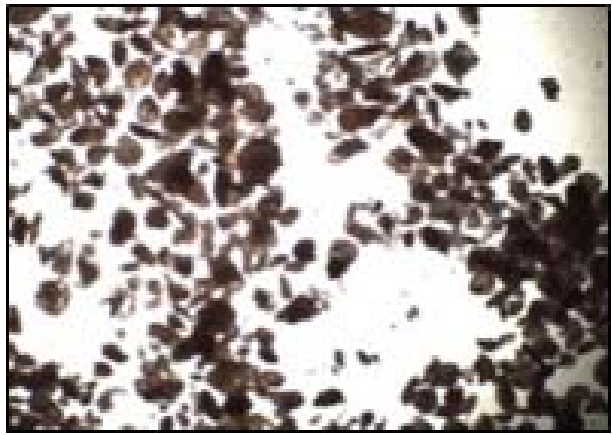

3(b) Microscopic Image of Pb (II)-Loaded TPVSP

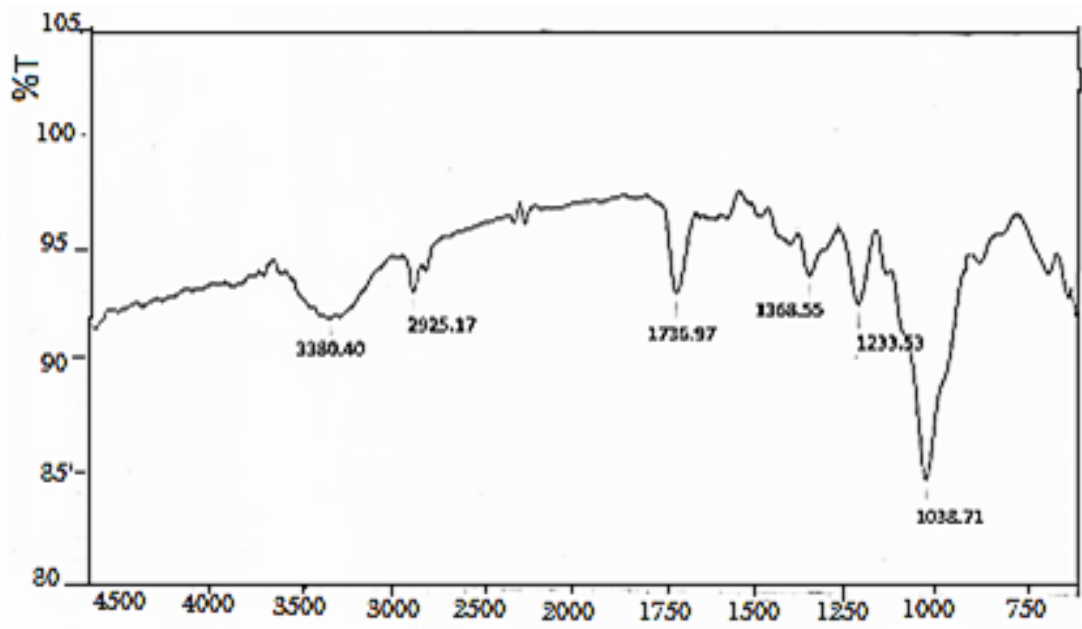

Fig. 4(a) FT-IR Spectra- Untreated Pistachio vera shell powder 


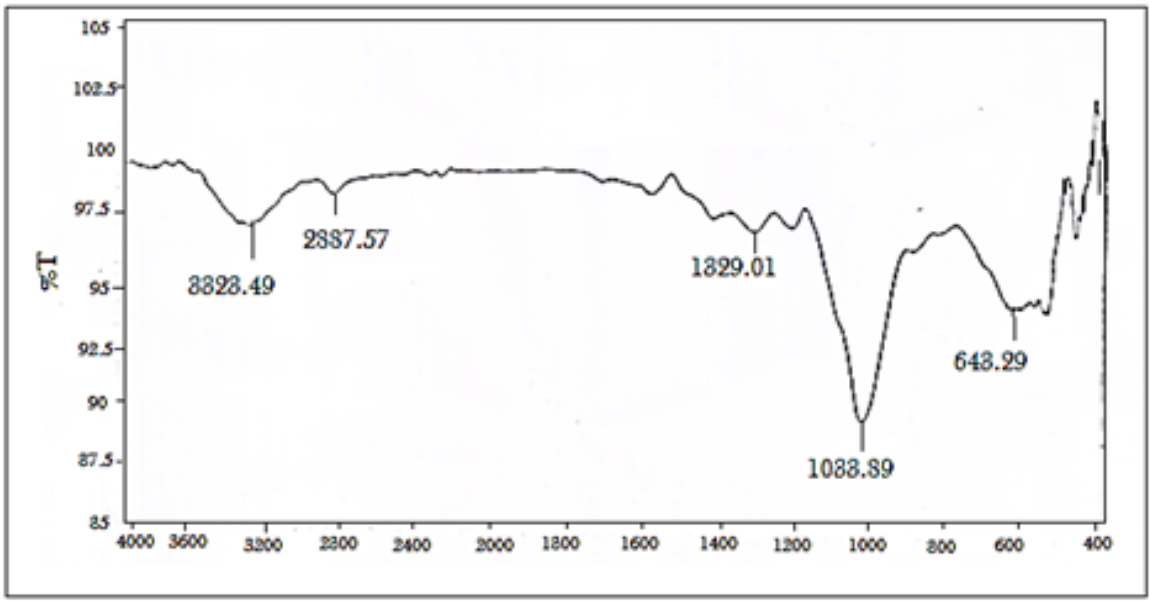

4(b) FT-IR Spectra- Treated Pistachio vera shell powder

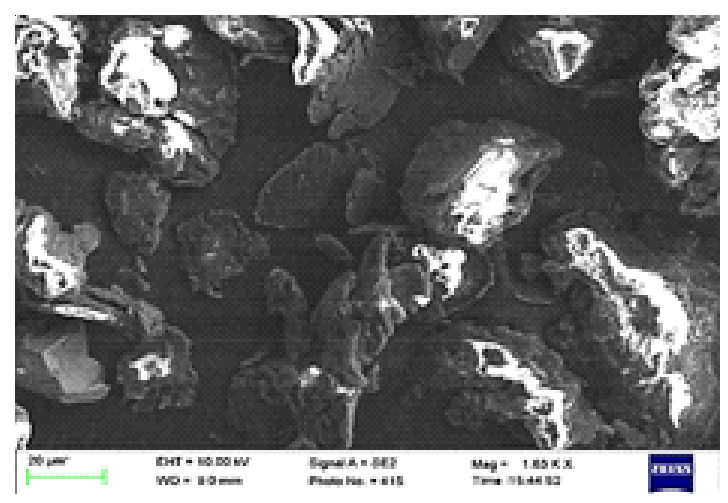

Fig. 5(a) SEM of Unloaded TPVSP

\section{EDAX Analysis}

The EDAX spectra were recorded to analyse the elemental compositions of the unloaded

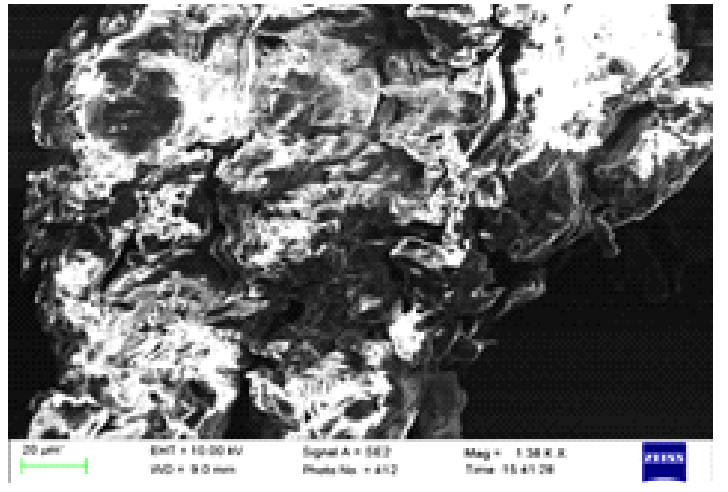

5(b) SEM of Pb (II)-Loaded TPVSP

and loaded TPVSP. The appearance of new peak at a value of $2.3 \mathrm{KeV}$ confirms the sequestration of $\mathrm{Pb}$ (II) ions with $2.5 \%$ weight is depicted in the Figure. 6 .

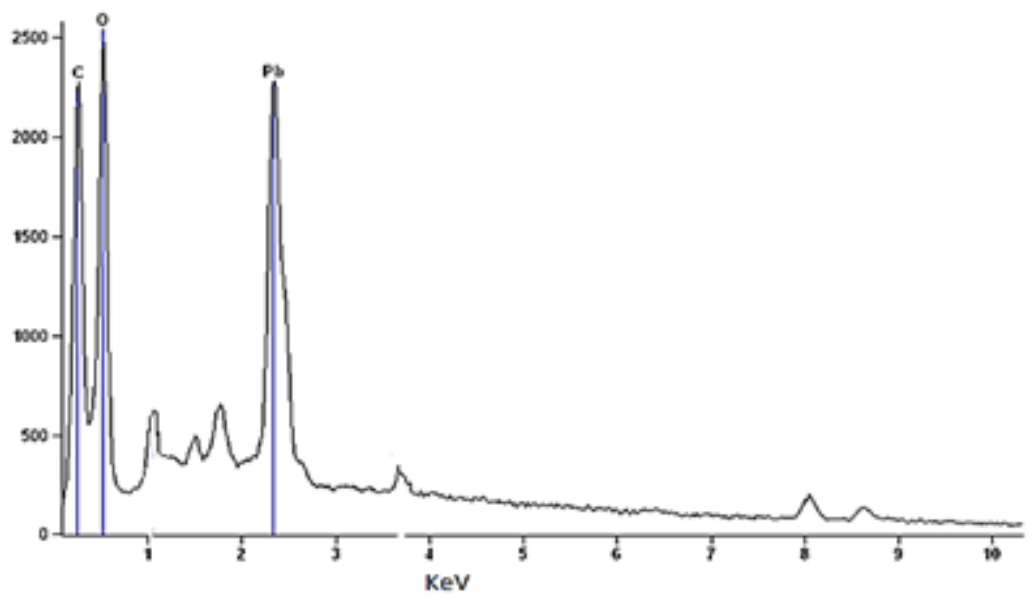

Fig. 6. EDAX Spectrum of $\mathrm{Pb}$ (II) loaded TPVSP 


\section{Effect of Particle Size}

The overall sorption capacity of any sorbent material is suggested as a function of particle size, probably indicating a better surface sorption phenomenon. A smooth steep curve indicating a greater sorption for amounts of lead (II) adsorbed by $0.18 \mathrm{~mm}$ is represented in Fig. 7 . Categorised particle sizes $(0.21 \mathrm{~mm}, 0.30 \mathrm{~mm}, 0.42$ $\mathrm{mm}$ and $0.71 \mathrm{~mm}$ ) is apparent,. Which clearly indicate that diminished particle size enhances the available surface area promoting better chelating ability. Also, significant spherical surfaces exhibit higher external mass transfer. Where marked metal sorption is facilitated due to this mass transfer factor ${ }^{15}$. Thenceforth, $0.18 \mathrm{~mm}$ dimension of TPVSP is fixed for the forthcoming experiments.

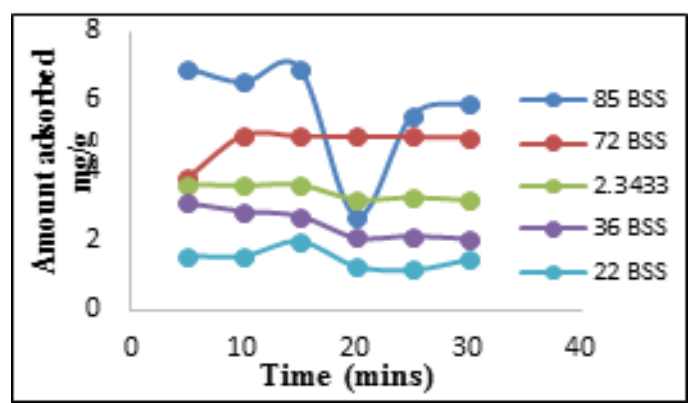

Fig. 7. Effect of Particle Size

\section{Effect of Dosage}

An increase in adsorbent dosage seems to have a great influence on the sorption process. Wherein it influences the number of binding sites available for adsorption. Sorption efficiency studied at varying doses 10, 25, 50, 75, $100 \mathrm{mg}$ for Pb (II)-TPVSP system is depicted in Fig. 8. A gradient rise in \% removal is observed at elevated magnitude corresponding with dosages. Availability of extended surface area16 at higher doses leads to enhanced sorption estimated as approximately $80.71 \%$ for $100 \mathrm{mg}$ of TPVSP. Thenceforth, $100 \mathrm{mg}$ is fixed as the optimised dose for forthcoming experiments.

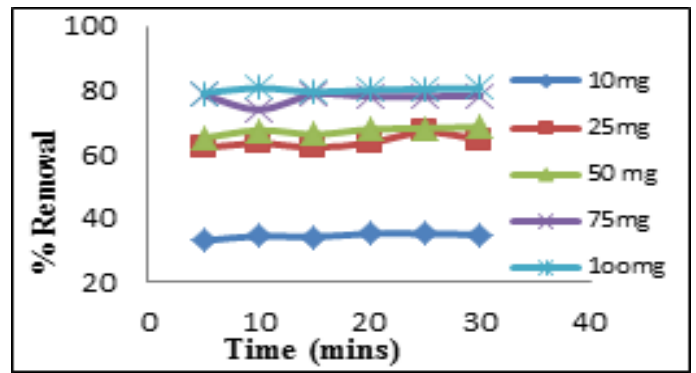

Fig. 8 Effect of Dosage

\section{Effect of Contact Time /Initial Concentration}

The influence of agitation time intervals at preset conditions and that of varying initial $\mathrm{Pb}$ (II) concentrations are shown in Fig. 9, wherein the observed curves reveal consistent increments in the amounts adsorbed. This may be due to the saturation in the sorption sites ${ }^{17}$ reaching an equilibrium state as emphasized by the linear nature after a contact time of 10 minutes. The plot implies that there is an increase in the initial $\mathrm{Pb}$ (II) concentrations $(10 \mathrm{mg} / \mathrm{L}-250 \mathrm{mg} / \mathrm{L})$ results in a reduction of percentage removal due to limited adsorption sites ratio between metal and TPVS. From these inferences, a contact of $10 \mathrm{~min}$. as predetermined time factor and $10 \mathrm{mg} / \mathrm{L}$ of $\mathrm{Pb}$ (II) as initial concentration are fixed for further studies.

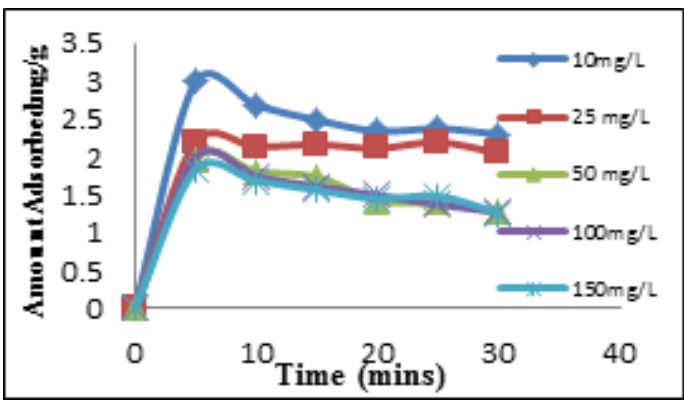

Fig. 9. Effect of Initial Concentration/ Contact Time

\section{Effect of $\mathrm{pH}$ onto sorption of $\mathrm{Pb}$ (II) ions}

To scrutinize the role of $\mathrm{pH}$ in removal efficiency of $\mathrm{Pb}$ (II) ions, the initial $\mathrm{pH}$ of the adsorbate solutions was varied in the range of 3-9. The adsorption capacities were found to be lower at low $\mathrm{pH}$ and increased with increase in $\mathrm{pH}$. This can be explained with competitive adsorption of $\mathrm{H}_{3} \mathrm{O}+$ ions and metal ions for the same active sorption site ${ }^{18}$. The adsorption study could not be carried out experimentally at $\mathrm{pH}$ values higher than 8 due to the precipitation of lead as $\mathrm{Pb}(\mathrm{OH})_{2}$. It is evident from the Fig. 10, that, the removal percentage of $\mathrm{Pb}$ (II)ions are maximum at $97.71 \%$, at fixed $\mathrm{pH}$ environment.

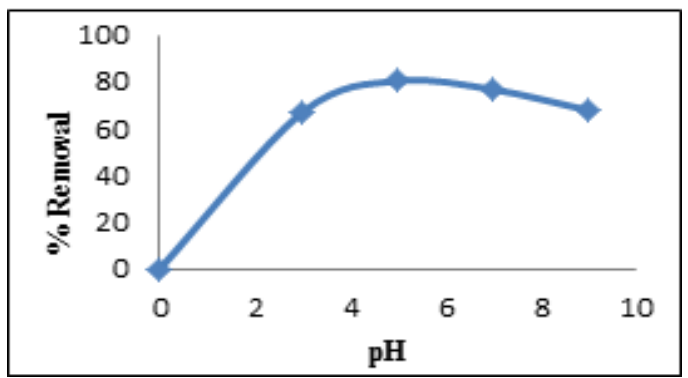

Fig. 10. Effect of pH 


\section{Effect of Temperature}

Percentage removal of $\mathrm{Pb}$ (II) ions registered a gradual inclination towards metal ions with temperature (293 K to $333 \mathrm{~K}$ ) as obvious from Fig. 10 which indicates the effectiveness of exothermicity. The elevation in the adsorption capacity of TPVSP at higher temperatures may be attributed to the desolvation of adsorbing species, increase in the mobility of adsorbate species to get sorbent extensively, enlargement of sorbent pore size or due to decrease in the boundary layer thickness surrounding the sorbent, so that the mass transfer resistance of adsorbate in the boundary layer is retarded ${ }^{19}$.

\section{Effect of Cations / Anions}

Response of $\mathrm{Pb}$ (II)-TPVSP system under the influences of varied concentrations $(0,10,25$, $50,75,100 \mathrm{mg} / \mathrm{L})$ of cations $\left(\mathrm{Na}^{+}, \mathrm{K}^{+}\right)$and anions
$\left(\mathrm{Cl}^{-}, \mathrm{SO}_{4}{ }^{2-}\right)$ was performed to assess their impacts. Tabulated values imply $1 / 3^{\text {rd }}$ ratio (Table. 3 ) of decline under varying $\mathrm{Na}^{+}$ion environments with respect to $\mathrm{K}^{+}$ions respectively. The reason for enhancement of $\mathrm{Na}^{+}$may be due to electrostatic repulsion and degree of hydration ${ }^{20}$. Similar studies on the effect of diverse ions have been reported by Deepak. J. Garoke et al., Similarly, Chloride ions recorded a marked inhibition in percentage removal of $\mathrm{Pb}(\mathrm{II})$ by TPVSP than $\mathrm{SO}_{4}{ }^{2-}$ ions, which shall be due to the preferential formation of chloro complexes by the chosen sorbate, which leads to less availability of $\mathrm{Pb}(\mathrm{II})$ ions to get sorbed on TPVSP substrate. Kenneth L. Dorris and Shyam S. Shukla in their sorption studies of aqueous solution of cadmium using crab shell ${ }^{21}$. This is supported by the findings of Pehlivan et al., ${ }^{22}$ where effect of chloride ions have more affinity towards the free metal ions than the adsorbent to form salts $\left(\mathrm{PbCl}^{+}\right.$and $\left.\mathrm{PbCl}_{2}\right)$.

Table. 3: Effect of Cations and Anions

\begin{tabular}{ccccc}
\hline \multirow{2}{*}{ Concentrations of ions $(\mathrm{mg} / \mathrm{L})$} & \multicolumn{4}{c}{ Percentage of Adsorption (\%) } \\
\cline { 2 - 5 } & $\mathrm{Na}+$ & $\mathrm{K}+$ & $\mathrm{Cl}$ & $\mathrm{SO}_{4}^{{ }^{2 "}}$ \\
\hline 0 & 80.71 & 80.71 & 80.71 & 80.71 \\
10 & 88.22 & 89.42 & 89.95 & 90.64 \\
25 & 90.54 & 91.15 & 92.74 & 93.89 \\
50 & 95.81 & 95.82 & 94.15 & 95.47 \\
75 & 99.75 & 98.62 & 95.58 & 99.63 \\
100 & 99.89 & 99.09 & 98.62 & 99.95 \\
\hline
\end{tabular}

\section{Effect of Co-ions}

Presence of Co-ions $\left(\mathrm{Cr}^{6+}, \mathrm{Cu}^{2+}, \mathrm{Ni}^{2+}, \mathrm{Cd}^{2+}\right)$ were observed to retard the sorption rate of TPVSP at a $\%$ reduction of $80 \% \mathrm{~Pb}(\mathrm{II})$ removal registered in the absence of Co-ions. Among the four Co-ions,
$\mathrm{Cr}^{6+}$ exhibited pronounced hindrance in the removal of $\mathrm{Pb}(\mathrm{II})$ compared to the studies with other three cations. This is because of greater the solvation property of $\mathrm{Cr}^{6+}$ resulting out of its hydration ${ }^{23,24}$.

Table. 4: Effect of Co-ions

\begin{tabular}{lccccc}
\hline Metal & \multicolumn{4}{c}{$\%$ Removal } \\
\hline \multirow{2}{*}{$\begin{array}{c}\text { Absence of Co-ions } \\
\text { AlI })\end{array}$} & $\mathrm{Cr}(\mathrm{VI})$ & $\mathrm{Cu}(\mathrm{II})$ & $\mathrm{Ni}(\mathrm{II})$ & $\mathrm{Cd}(\mathrm{II})$ \\
& 80.71 & 45.14 & 63.22 & 70.6 & 79.30 \\
\hline
\end{tabular}




\section{Adsorption Isotherms}

An adsorption isotherm is characterized by certain constant values that express the surface properties and also the affinity of the sorbent. Adsorption isotherm data of $\mathrm{Pb}(\mathrm{II})$ ion was investigated to study the linear fit of Langmuir and Freundlich models. Experimental data and the predicted equilibria curves using the non-linear method for the two-equilibrium isotherms, Langmuir and Freundlich are depicted in Fig. 12 and 13 respectively. Better linearity was exhibited by Freundlich isotherm than Langmuir. Since, the $\mathrm{K}_{\mathrm{F}}$ and $\mathrm{n}$ values derived from the intercepts and slopes of the straight line indicate the adsorption capacity and the nature of sorption respectively. The value of $n>1$ implies favourable nature of adsorption. Similar trends were also observed by Gulnaz et al.,25

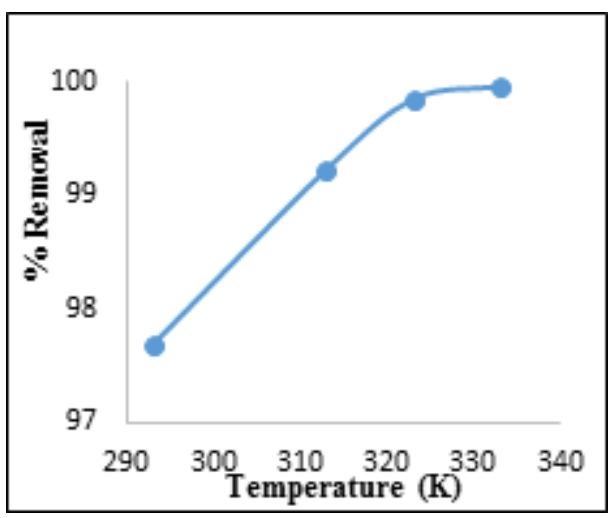

Fig. 11. Effect of Temperature

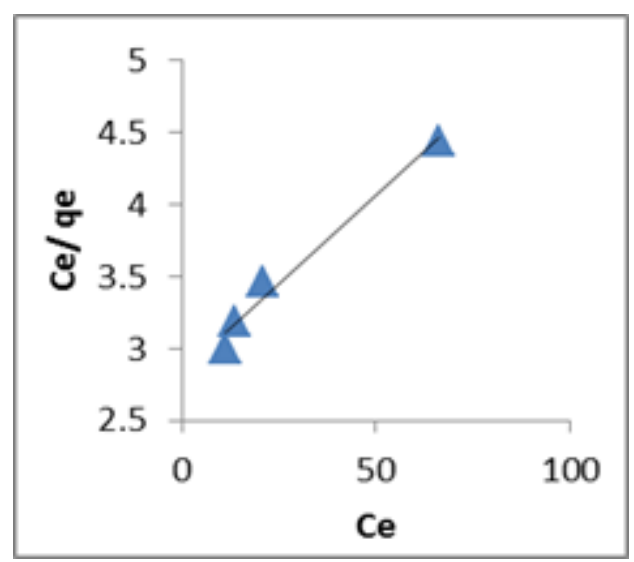

Fig. 12. Langmuir Isotherm

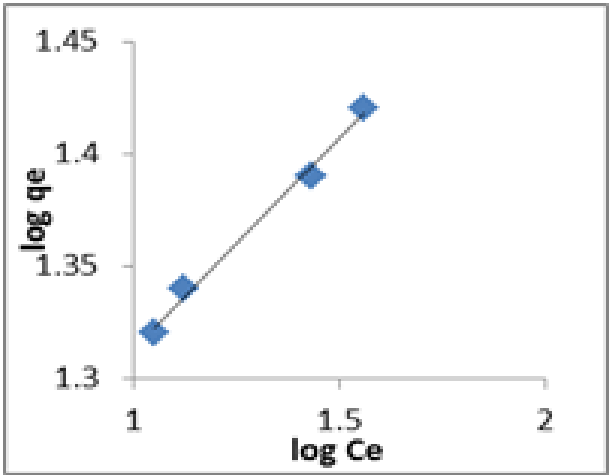

Column Studies

Quantification of Batch results were verified through column experiments. A column was designed of cylindrical glass tube; with an inner diameter of $2.5 \mathrm{~cm}$ and a height of $30 \mathrm{~cm}$. Sorbent materials were packed between two supporting layers of glass wool, spread with the glass beads at the top of the already packed glass wool layer placed at the bottom. The step ups of packing are glass wool layer ( $3 \mathrm{~cm}$ thickness), glass beads ( $2 \mathrm{~cm}$ thickness), TPVSP (40 g: $6 \mathrm{~cm}$ height), glass wool ( $1 \mathrm{~cm}$ thickness). These materials were loaded from the top of the column and allowed to settle by gravitational force. The bottom of the column was fitted with flow adjustable knob to control the flow rate.

An increase of 2.5 times in adsorption of $\mathrm{Pb}$ (II) ions was observed ensuring the bulkiness of the method at an optimised flow bed conditions: $100 \mathrm{ml} / 10 \mathrm{~min}$. flow rate. The column set up exhausted after a collection of 30 litres where only $45 \%$ removal remained constant, followed by desorption / regeneration studies $(100 \mathrm{mg} / \mathrm{L}$ aqueous solutions of $\mathrm{Pb}$ (II) ions).

\section{Desorption studies}

Desorption studies explores the probability of recycling the adsorbents and reclamation of the metal ions. Observance of adsorbate on the sorbent species can either be through physical bonding/ ion exchange or a combination of both. In the case of former, the loosely bound sorbate molecules can be desorbed easily, mostly with distilled water. Thence, in this judgement the percentage removal of $\mathrm{Pb}(\mathrm{II})$ ions assessed desorption at $94.2 \%$ through $0.1 \mathrm{~N} \mathrm{HCl}$. It is evident from the recorded observations, that the regenerated sorbents have good sorptive characteristics with appreciable reproducibility. 


\section{CONCLUSION}

The current investigation deals with the utilization of Pistachio vera shell (PVS), an agro waste material for the adsorption of $\mathrm{Pb}(\mathrm{II})$ ions. Pistachio vera shell powder was prepared from its raw material, which was treated using $0.1 \mathrm{~N} \mathrm{HCl}$ and $0.1 \mathrm{~N} \mathrm{NaOH}$ to enhance its sorption efficiency. The physiochemical characteristic studies viz., $\mathrm{pH}$, conductivity, moisture content, bulk density, specific gravity, ash content and elements $(\mathrm{C}, \mathrm{H}, \mathrm{N}, \mathrm{S})$ were determined using specified methods. Surface morphological studies, elemental compositions were analysed using FT-IR, SEM and EDAX respectively for both unloaded and loaded sorbent species. Variations in porosity structure through SEM analysis and the appearance of $\mathrm{Pb}(\mathrm{II})$ peaks in the EDAX spectra supported the positive adsorption. Operating factors like particle size, initial $\mathrm{Pb}$ (II) ion concentration, dosage, $\mathrm{pH}$ of the solutions and temperatures were optimised to ensure best sorption capacity of TPVSP $(80 \%)$ through batch equilibration experiments. Isothermal analysis laid emphasis on the adsorption pattern to be lineated with multilayer adsorption. Continuous column studies for quantitative assessment of $\mathrm{Pb}$ (II) ion removal from the bulk of the solution registered a maximum of $99 \%$. Desorption followed by regeneration studies were performed to estimate the extent of exhaustive nature of the packed material. To conclude, it is evident from the made observations and recorded values that the treated Pistachio vera shell powder (TPVSP) is a promising adsorbent for the removal of $\mathrm{Pb}$ (II) ions, being a viable material for treatment of industrial discharges.

\section{REFERENCE}

1. Sastry, S. V. A. R.;Shankar, B. S.; Kishore, S. V. S. Int. J. Comput. Engg. Res., 2013, 03, 676-78.

2. Sheibani, A.;Zare-khormizi, M.; Ind. J. Chem. Tech., 2012, 19, 48-51.

3. Rao, M. M.; Ramana, D. K.; Seshaiah, K.: Wang, M. C.; Chien, S. W. C;. J. Haz. Mat., 2009, 166, 1006-1013.

4. Aghajani, I. P.; Bahmani-androod, S. J.Bio.\& Env.sci., 2014, 5, 170-176.

5. Turan, N. G,; Clean-soil,air,water., 2011, 39(5), 475-481.

6. Issabayeva, G.; Kheireddine, M.; Meriam, N.; Desal., 2010, 262 ,94-98.

7. Muslim, A.; Devrina, E.; Fahmi, H.; J. Engg. Sci. Tech., 2015, 10, 1654-1666.

8. Ozc, D.; J. Haz.Mat. 2009, 168 ,1118-1125.

9. Peyman, L.; Mahmoudi, A.; Ghaffari, H.; Int.J. Agl. Crop Sci., 2013.

10. Saka, C.; Sahin, O.; Kucuk, M. M.; Int. J. Environ. Sci. Technol., 2012, 9, 379-394.

11. Sudha, R.; Premkumar, P.; Int. J. Chem. Tech. Res. 2016, 9, 47-57.

12. Ayse Eren Putun.; Varol. Energy., 27, 703-713

13. Mehrasbi, M. R.; Farahmandkia, Z.;
Taghibeigloo, B.; Taromi, A.; Water. Air. Soil Pollut., 2009, 199, 343-351.

14. Parlayici, S.; Pehlivan, Environ. Monit. Assess., 2015, 187, 763.

15. Sastry, S.V.A.R.; Shyam Shankar, B.; Kishore,S.V.S.; Int. J.Comput. Engg., 2013, 03(6).

16. Venkatesan, G.; Senthilnathan, U.; Research Journal of Chemistry and Environment., 2013,17, 3-8.

17. Turan, N. G. Clean-soil,air,water., 2011 , 39 (5), 475-481.

18. I.N.Jha, Leela lyengar.; A.V.S. Prabakar Rao, J.; Env. Engg., 1988, 114 (4), 962 - 974.

19. Aik Chong Lua.; Ting Yang. J.Colloid Interface Sci., 2004, 274, 594-60

20. Harikishore Kumar Reddy, D.; Seshaiah, K.; Reddy, A.V.R.; Madhava Rao, M.; Wang, M.C.; J. Hazard. Mater., 2010, 174, 831-838.

21. Pandey, P. L.; Kankal, S. B.; Jadhav, M. V.; Int. J. Sci. Res., 2014, 4, 12

22. Pehlivan, E.; Cetin, S.; Yanik, B.H.; J. Haz. Mat., 2006, 135, 193 - 199.

23,24.Emine Malkoc.; Yasar Nuhoghu; J. Haz. Mat. 2006, 135, 1-3, 328-336

25. Gulnazia.; Aroua,Sulaiman, Desal., 2010, 262, 94-98. 